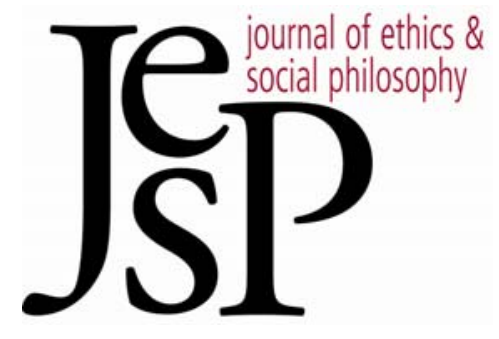

\title{
WHEN WILL YOUR CONSEQUENTIALIST FRIEND ABANDON YOU FOR THE GREATER GOOD?
}

BY SCOTT WOODCOCK 


\section{When Will Your Consequentialist Friend Abandon You for the Greater Good?} Scott Woodcock

CCORDING TO A WELL-KNOWN OBJECTION to consequen-
tialism, the answer to the preceding question is alarmingly
straightforward: your consequentialist friend will abandon you the minute that she can more efficiently promote the good via options that do not include her maintaining a relationship with you. Moreover, for consequentialists living in relatively affluent circumstances, this will apparently be a routine occurrence. Friendship is surely a good worth promoting, either for instrumental reasons or for its own sake, but the sum of goodness to be promoted at any particular moment through friendships among the affluent will presumably amount to less than the sum that can be promoted by diverting time and resources to persons in dire need of aid. Thus, the obligation to maximize the good creates a persistent source of tension for consequentialists caught between their commitment to their moral theory and the personal commitments that bind them to their friends. The tension is not exclusively related to consequentialism, but the teleological nature of the theory makes it a conspicuous target for critics to set their sights upon.

The most prominent response from consequentialists has been to emphasize the profound value of friendship for human agents and to remind critics of the distinction between a theory's criterion of rightness and what it recommends as effective decision-making procedures. ${ }^{1}$ This is not the only way to respond to what I will refer to as the "friendship objection." Adopting rule-consequentialism, satisficing consequentialism or agent-centered prerogatives will also help to reduce the tension between friendship and the rigorous demands of consequentialism. ${ }^{2}$ However, invoking the distinction

1 Examples include: J.S. Mill, Utilitarianism, Roger Crisp ed. (Oxford: Oxford University Press, 1998), ch. 2; Henry Sidgwick, The Methods of Ethics, $7^{\text {th }}$ ed. (Indianapolis: Hacket, 1981), bk. 4, ch. 5; G.E. Moore, Principia Ethica, Rev ed. Thomas Baldwin (Cambridge: Cambridge University Press, 1993), ch. 5; R.E. Bales, "Act-Utilitarianism: Account of Right-Making Characteristics or Decision-Making Procedures?" American Philosophical Quarterly 8 (1971): 257-65; R.M. Hare, Moral Thinking: Its Levels, Method and Point (Oxford: Clarendon Press, 1981); and Derek Parfit, Reasons and Persons (Oxford: Clarendon Press, 1984). Examples pertaining to friendship include: Peter Railton, "Alienation, Consequentialism, and the Demands of Morality," Pbilosophy \& Public Affairs 13 (1984): 134-71; David Brink, "Utilitarian Morality and the Personal Point of View," The Journal of Philosophy 83 (1986): 417-38; Philip Pettit and Geoffrey Brennan, "Restrictive Consequentialism," Australasian Journal of Philosophy 64 (1986): 438-55; and Roger Crisp, "Utilitarianism and the Life of Virtue," The Philosophical Quarterly 42 (1992): 139-60.

2 The most persuasive articulation of rule consequentialism is: Brad Hooker, "RuleConsequentialism," Mind 99 (1990): 67-77, "Rule-Consequentialism and Obligations toward the Needy," Pacific Philosophical Quarterly 79 (1998): 19-33, and Ideal Code, Real World (Oxford: Oxford University Press, 2000). The most influential defense of satisficing consequentialism is Michael Slote, "Satisficing Consequentialism," Proceedings of the Aristotelian Society, Sup. 58 (1984): 139-63. Further discussion of satisficing can be found in Michael Byron ed., Satisficing 
between criteria of rightness and decision-making procedures is the most economical response to the friendship objection for those who prefer more generic forms of act-consequentialism, i.e. forms that do not involve modifications of the basic criterion that a right action is one which best promotes goodness given the alternatives available to an agent at a particular time. One simply recommends whatever decision procedures are most effective in terms of maximizing the good; then one relies on the empirical hypothesis that lives without friendship are so alienating for human beings that more goodness is promoted by agents with friends than agents who act on direct consequentialist decision procedures.

By emphasizing this feature of (sensible) act-consequentialism, the objection that consequentialists are incapable of maintaining friendships is defused, for such agents can be directed - to the extent that empirical details permit - to act preferentially for the sake of their friends instead of being exclusively motivated by their consequentialist criterion of rightness. In effect, the substance of the friendship objection becomes an upgrade instead of a liability. If friendship is so vital for human lives that its elimination is catastrophic for our integrity as moral agents, then this is all the more reason for consequentialists to ensure that their decision procedures (understood to include broad dispositions, character traits, virtues, motives, etc.) successfully capture this good and avoid the self-defeating results that arise when agents divest themselves of their personal relationships.

This response to the friendship objection has generated considerable interest, yet an important question remains curiously overlooked in the resulting literature. This is the issue of when a consequentialist will break from indirect methods of promoting the good and revert back to a direct form of decision-making. ${ }^{3}$ It might seem as if this issue must be addressed before consequentialism's accommodation of friendship can be evaluated, but this has not been the case. Instead, the issue is often postponed because the objection tends to be stated as an in-principle objection to the way friendship is

and Maximizing (Cambridge: Cambridge University Press, 2004). Samuel Scheffler introduced agent-centered prerogatives in The Rejection of Consequentialism, Rev. Ed. (Oxford: Oxford University Press, 1994), though they play a key role in Tim Mulgan's The Demands of Consequentialism (Oxford: Oxford University Press, 2001). An additional option is for one's criterion of rightness to track motives or expected consequences after the value of friendship and our opportunities to promote it are fully appreciated. See R.M. Adams, "Motive Utilitarianism," The Journal of Philosophy 73 (1976): 467-81 and Frank Jackson, "Decision-Theoretic Consequentialism and the Nearest and Dearest Objection," Ethics 101 (1991): 461-82.

${ }^{3}$ Note that I will refer to "indirect measures" within consequentialism without invoking the term "indirect consequentialism." As apt as the latter term may appear, it is tainted by an unfortunate ambiguity in the literature. Some philosophers use the term to refer to forms of consequentialism that employ a division between a criterion of rightness and decisionprocedures that indirectly lead to the long-term satisfaction of the criterion. Others use the term to refer to versions of consequentialism in which a criterion of rightness tracks goodness indirectly via indicators such as rules rather than acts. I am concerned with the former of these two types of "indirect" consequentialism. 
incorporated within consequentialism rather than an objection to any particular point when empirical details force consequentialists to act against the bonds of their friendships.

But the question of when consequentialists ought to revert back to direct methods of promoting the good at the expense of their friendships is important, for even if the in-principle objection to incorporating friendship within consequentialism can be avoided, a practical objection looms if empirical circumstances are such that progressive versions of consequentialism still end up dissolving friendship in non-ideal contexts. ${ }^{4}$ For many, it is seriously counterintuitive for friendship to be precluded by the practical application of an ethical theory in current circumstances regardless of whether the theory is consistent with friendship as a matter of principle.

Thus, my aim in this paper is to survey the empirical considerations at stake for a consequentialist account of friendship in an effort to begin working toward an answer to the question of when a consequentialist ought to abandon her obligations to her friends. I must emphasize, however, that I will not offer a simple answer to this question - quite the contrary. My point will be that simple answers to this question should be avoided because the empirical factors in play are more complex than is normally acknowledged. I begin with a brief overview of the literature on consequentialism and friendship before arguing against a trend in this literature to endorse rigid profriendship dispositions. I then offer an analysis of some empirical factors at stake for this debate in an effort to highlight the intricacy of a consequentialist's justifiable commitments to her friends. This, I hope, will serve as a remedy for the tendency to opt for clear-cut answers and thereby fail to provide the strongest case for reconciling consequentialism and friendship.

I

The problem that friendship generates for consequentialism is closely related to the more general problems of integrity and demandingness. Thus, the "friendship objection," as I will describe it, gained widespread influence through work produced by philosophers such as Bernard Williams, Michael Stocker and Susan Wolf. ${ }^{5}$ Their respective targets were not limited to consequential-

${ }^{4}$ By "non-ideal contexts," I just mean circumstances in which there are enough persons in dire need of aid that a consequentialist cannot simply focus on maximizing goodness within the localized sphere of her own friends and family.

5 See Bernard Williams, "A Critique of Utilitarianism," in J.J.C. Smart and Williams, Utilitarianism: For and Against (Cambridge: Cambridge University Press, 1973), 77-150; "Persons, Character and Morality" in Moral Luck (Cambridge: Cambridge University Press, 1981), 1-19; Michael Stocker, "The Schizophrenia of Modern Ethical Theories," The Journal of Pbilosophy 73 (1976): 453-66; "Friendship and Duty: Some Difficult Relations," in Identity, Character and Morality: Essays in Moral Psychology, Owen Flanagan and Amélie Oksenberg Rorty eds. (Cambridge, Mass.: MIT Press, 1990), 219-234; Susan Wolf, "Moral Saints," The Journal of Pbilosophy 79 (1982): 419-39; "Review of Williams: The Deflation of Moral Philosophy," Etbics 97 (1987): 821-33; and "Morality and Partiality," Pbilosophical Perspectives 6 (1992): 243-59. For 
ism, but a shared source of concern emerged for the inner lives of consequentialist agents. The concern was that if one were continuously motivated by an imperative to promote the most agent-neutral value possible, one would become alienated from the aims that make our lives significant from our own personal points of view. One would be reduced to a kind of relentless moral fanatic - one whose choices are wholly determined by the opportunities for promoting goodness specified by the environment in which she happened to exist. The concern here was not merely that a life of this kind is unappealing. The concern was that this existence is appropriate only for creatures like termites and honeybees, and that the consequentialist expectations for moral agency are incompatible with the features that make our lives minimally worthwhile.

In the wake of this general concern regarding integrity, friendship has emerged as an illustrative example of the kinds of personal projects that are apparently ruled out by living a consequentialist life. Genuine friendship requires significant levels of partiality, intimacy and commitment that cannot be achieved by agents seeking to maximize general goodness at every available opportunity, and our familiarity with these requirements (and what is lost if they are not fulfilled) provides a vivid representation of consequentialism's inability to directly endorse a recognizable human life. 6

Faced with this objection, however, consequentialists had only to emphasize what was already present in canonical articulations of the theory: direct implementations of the consequentialist criterion of rightness will be self-defeating; hence, maximizing the good ought to proceed via indirect methods that disconnect the criterion of rightness from the decision procedures

other influential articulations of the view that theories like consequentialism are ill-equipped to appreciate the special value of friendship, see Lawrence Blum, Friendship, Altruism and Morality (Boston: Routledge, 1980); John Cottingham, "Ethics and Impartiality," Pbilosophical Studies 43 (1983): 83-99; and Marilyn Friedman, What Are Friends For? Feminist Perspectives on Personal Relationships and Moral Theory (Ithaca, NY: Cornell University Press, 1993).

${ }^{6}$ In what follows, I work with a provisional understanding of friendship as a relationship characterized by features such as mutual concern, intimacy, partiality and the pursuit of shared activities. By relying on this very general view of friendship, I do not mean to discount detailed examinations of the nature of friendship and its special characteristics. Rather, I rely on an equivocal view of friendship because any praiseworthy relationship that involves partiality is sufficient to create an objection to consequentialism. (In this respect, the objection is more accurately described as a "partiality" objection, since it is ultimately about whether consequentialism can justify special treatment for anyone if doing so involves suboptimal acts. See Julia Driver, "Introduction," Utilitas 13, (2001): 137-151, 137.) For a survey of recent work on friendship, see Neera Kapur Badhwar, Friendship: A Pbilosophical Reader (Ithaca, N.Y.: Cornell University Press, 1993). Especially noteworthy examinations of friendship include Elizabeth Telfer, "Friendship," Proceedings of the Aristotelian Society 71 (1970): 22341; John Cooper, "Friendship and the Good in Aristotle," The Pbilosophical Review 86 (1977): 290-315; David Annis, "The Meaning, Value, and Duties of Friendship," American Pbilosopbical Quarterly 24 (1987): 349-56; Neera Badhwar, "Friends as Ends in Themselves," Pbilosophy and Phenomenological Research 48 (1987): 1-23; and Dean Cocking and Jeanette Kennett, "Friendship and the Self," Ethics 108 (1998): 502-27. 
agents are encouraged to follow. If friendship is essential to avoid a breakdown in human integrity, then consequentialists ought to participate in authentic friendships rather than transparently viewing their "friends" as instrumental opportunities for the fulfillment of an underlying criterion of rightness.

Peter Railton provides what has come to be the most prominent articulation of this method of incorporating friendship within consequentialism. ${ }^{7} \mathrm{~A}$ representative agent of his "sophisticated consequentialism" is someone who maintains a standing commitment to a consequentialist criterion of rightness but who is not dedicated to any particular form of decision-making. Thus, a sophisticated consequentialist agent will be moved to act by whatever motives, aversions, dispositions and deeply internalized character traits are most likely to maximize goodness over time. These will include non-maximizing facets when necessary and will therefore potentially conflict with the agent's base commitment to a consequentialist criterion of rightness, but Railton notes that this agent will be bound by an underlying counterfactual condition: "While he ordinarily does not do what he does simply for the sake of doing what is right, he would seek to live a different sort of life if he did not think his were morally defensible." 8 The agent can therefore justify continued participation in friendships because they are part of an overall life that, ex bypothesi, will best promote the good. ${ }^{9}$

For many, Railton provides a sufficiently compelling depiction of a sophisticated consequentialist to diffuse the friendship objection. Others, however, are not convinced that friendship is compatible with his counterfactual condition, since it leads agents to choose against the bonds of friendship if they can lead a more efficient consequentialist life by doing so. In other words, critics are not satisfied that the loyalty associated with friendship can be captured by agents who are only contingently dedicated to preserving their relationships with their friends. For Neera Badhwar, the fact that consequentialism ultimately justifies friendship in instrumental terms makes it logically inconsistent with the motives necessary for friends to see each other as ends

\footnotetext{
7 Railton, "Alienation.”

8 Ibid., 151.

${ }_{9}^{9}$ Many factors are involved in this hypothesis. In what follows, I will primarily work with the assumption that a human life lived without close personal relationships will tend to precipitate an emotional burnout of significant enough proportions that the agent will end up promoting less impartial goodness on the whole than if she engaged in such relationships. This is not to discount other ways in which friendship is morally significant. For example, Marilyn Friedman argues that friendship contributes to moral growth by leading agents to adopt new standpoints for moral inquiry through the perspectives of their friends. ("Friendship and Moral Growth," The Journal of Value Inquiry 23 (1989): 3-13.) However, if desperate poverty exists, many of the ways in which friendship generates goodness will be outweighed by the opportunity to save lives. The ability to prevent emotional burnout is in this respect unique, because it is not affected by the increased demands of non-ideal circumstances.
} 
in themselves. ${ }^{10}$ For William Wilcox, it is not psychologically feasible to reconcile a consequentialist counterfactual condition with the strong sense of personal commitment required for friendship. ${ }^{11}$ For Dean Cocking and Justin Oakley, as long as the counterfactual condition requires agents to terminate friendships when more efficient consequentialist options are available, the motivational dispositions of even sophisticated consequentialists are not compatible with the nature of authentic friendships. ${ }^{12}$ In each case, the root complaint is that key aspects of friendship are not compatible with the fact that consequentialist agents must, at some level, view their friendships as dispensable under certain conditions.

All three of these objections to Railton's defense of consequentialism claim to be providing in-principle arguments against the possibility of reconciling consequentialism with friendship. None of them attempt to identify thresholds at which consequentialist agents will, counterintuitively, terminate friendships; they instead attempt to demonstrate that the very structure of the consequentialist endorsement of friendship is defective. I am not convinced that these arguments are persuasive as in-principle objections to the structure of consequentialism, yet they do successfully identify a practical problem for implementing indirect measures within an overall commitment to the theory: in what circumstances will sophisticated agents break from ordinary decision procedures and revert to a direct consequentialist evaluation of the options available? For advocates of two-level versions of consequentialism, this is a critical question with pitfalls on both sides. If, on the one hand, consequentialist agents apply a counterfactual condition test too often when it comes to evaluating different paths available in life, then these agents will fall prey to the self-defeating outcomes so familiar to direct implementations of the theory. If, on the other hand, such agents limit themselves to applying the counterfactual condition test in rare circumstances, and thus prevent themselves from evaluating their options in terms of a consequentialist criterion of rightness, then they risk being queerly bound to the authority

10 See "Why It Is Wrong to Be Always Guided by the Best: Consequentialism and Friendship," Ethics 101 (1991): 483-504. For a response, see Paul Gomberg, "Friendship in the Context of a Consequentialist Life," Ethics 102 (1992): 552-54.

11 See "Egoists, Consequentialists, and Their Friends," Philosophy and Public Affairs 16 (1987): 73-84. A direct response is found in Alastair Norcross, "Consequentialism and Commitment," Pacific Philosophical Quarterly 78 (1997): 380-403. For observations of the fact that the psychological problems related to self-effacing criteria of rightness are not specific to consequentialism, see Cynthia Stark, "Decision Procedures, Standards of Rightness and Impartiality," Noûs 31 (1997): 478-95; Thomas Hurka, Virtue, Vice, and Value (Oxford: Oxford University Press, 2001), 246-49; and Simon Keller, "Virtue Ethics Is Self-Effacing," Australasian Journal of Philosophy 85 (2007): 221-31.

12 See "Indirect Consequentialism, Friendship, and the Problem of Alienation," Ethics 106 (1995): 86-111. Similar views are expressed by Troy Jollimore, "Friendship without Partiality?" Ratio 13 (2000): 69-82; and Damian Cox, "Integrity, Commitment, and Indirect Consequentialism," The Journal of V alue Inquiry 39 (2005): 61-73. 
of indirect decision procedures in the face of clear opportunities for maximization.

Sophisticated consequentialism therefore faces a dilemma. It is either (a) drawn back into direct decision-making and collapsing into a theory so ceaselessly demanding that it dissolves friendship, or (b) oddly committed to decision procedures that sanction gratuitously suboptimal acts of friendship. There is no reason why consequentialism is unable, as a matter of principle, to reach an intermediate point between the pitfalls of this dilemma. In practice, however, it is a formidable challenge for which there is no widely accepted solution.

\section{II}

The most prominent response on behalf of Railton's proposed solution to the friendship objection comes from Elinor Mason. ${ }^{13}$ In her defense of indirect methods for promoting the good, she appropriately emphasizes the deep human need for emotional connections with others and the fact that a life lived with a disposition for friendship will generally promote more overall good than a life with a disposition to maximize at every available opportunity. In particular, she notes that "human nature is rather inflexible"14 and that, if faced with the choice between a disposition to terminate suboptimal relationships and a disposition to fully commit to such relationships, a consequentialist ought to choose the latter because she can then relax and be committed to her friends without feeling a need to constantly evaluate the optimality of these friendships. The former option, she says, will generate prohibitive feelings of distrust and alienation among one's friends and will subsequently undermine the special value of friendship.

According to Mason, then, the sophisticated consequentialist ought to possess a notably rigid pro-friendship disposition that precludes her from terminating friendships on grounds of suboptimality. The only cases in which she will terminate friendships are rather extreme, i.e. if circumstances are such that the general pro-friendship disposition is suboptimal and must therefore be discontinued. Mason presents an appropriately unusual example of this situation in which a consequentialist, Sam, contracts a disease that makes him aggressive, violent and a pathological liar. ${ }^{15}$ Sam ought to renounce his disposition for friendship, as it will no longer best promote the good, and one can imagine other odd cases in which abnormal circumstances invalidate the otherwise credible assumption that lives lived with friendship are consistent with promoting the good (e.g. evil demons that threaten to end the world unless agents become hermits, etc.). The point is that scenarios like

13 Elinor Mason, "Can an Indirect Consequentialist Be a Real Friend?” Ethics 108 (1998): 386-93.

14 Ibid., 389.

15 Ibid., 392. 
these are sufficiently rare that consequentialists can feel confident about maintaining dedicated commitments to their friends in their ordinary lives.

As a response to Cocking and Oakley, who allege that Railton's counterfactual condition will lead agents to "live a different kind of life" and terminate friendships the minute doing so will more efficiently promote the good, Mason's reading of sophisticated consequentialism effectively immunizes it from their criticism. The problem is that her solution comes at considerable cost. As Robert Card points out:

\begin{abstract}
Mason's thesis is implausible since it implies that it could or would be best that sophisticated consequentialists never consider renouncing particular friendships because they are suboptimal. This implies that if a friend attempts to draw me into a life of crime and self-indulgent drug use, I should not end the friendship, even if I believe both that I may succumb to the temptation and that my continuation of the friendship will not allow me to help the friend avoid these pitfalls. On Mason's account, I would only give up this friendship if I became convinced that it was best that I renounce my "pro-friendship" disposition itself, thereby in effect ending all my friendships. ${ }^{16}$
\end{abstract}

As familiar as drug use may be, further examples are also available to illustrate this key inadequacy of Mason's thesis. I have in mind cases where the welfare of third parties is jeopardized by a friendship instead of just the main participants in the relationship. For example, if a friend runs into financial difficulties and asks that I help him to embezzle money from innocent investors, it is clear both that (a) I ought to act against the loyalty generated by our relationship, and (b) even if this requires terminating the relationship with this particular friend, it need not involve renouncing a general disposition to have any friends at all. Less drastic examples can be found whenever friends are asked to lie in order to conceal infidelities, reasons for being late for work, etc. More sensational examples can be imagined when friends are asked to be complicit in activities involving injury or death for third parties. ${ }^{17}$ Regardless of how conclusively Mason's interpretation of sophisticated consequentialism can rebut the challenge from Cocking and Oakley, the examples of friendships that must be terminated without abandoning the disposi-

16 Robert Card, "Consequentialism, Teleology, and the New Friendship Critique," Pacific Pbilosophical Quarterly 85 (2004): 149-72.

${ }_{17}$ This is the situation so skillfully illustrated in Carol Reed's film The Third Man (1949), but many other films and works of literature can be cited to illustrate the principal point at stake. As Thomas Hurka points out, Casablanca (1942) is another classic film which suggests that personal relationships must ultimately be set aside for higher moral causes. Hurka makes this point in the context of comparing it to The English Patient (1996) which, as a film, breaks from the moral ambiguity of Michael Ondaatje's text and presents the mirror image of $\mathrm{Ca}^{-}$ sablanca by attaching inspirational music to Almazy's return to Katherine and thus sanctifying his prior decision to trade maps to the Nazis in exchange for a means of reaching her. See "The Moral Superiority of Casablanca over The English Patient," The Globe and Mail, January 25, 1997. 
tion for friendship itself generate a reductio from which her solution cannot recover. ${ }^{18}$

The assumption that constrains Mason to a choice between the collapse Cocking and Oakley predict and her proposed solution is the hypothesis that human nature is so rigid that the internalized behavioral dispositions to which consequentialists commit themselves render agents unable to deviate from their broad and inflexible guidance. In the case of friendship, the assumption implies that appropriately socialized humans will be committed to dispositions to honor the bonds of friendship that are entrenched so deeply that the possibility of critically evaluating their legitimacy on a case-by-case basis is precluded. Humans are, on this view, unable to adopt an intermediate strategy of relying on internalized dispositions in most situations, yet capable of reverting to direct evaluations of friendships in rare circumstances. One is either "trained" as a maximizer or as a follower of dispositions. No mixed strategy is presented as an option, making Mason's decision to opt for a rigid pro-friendship disposition a sensible choice.

There is something plausible and important about the enduring power of human socialization and the fact that it tends to leave us both (a) generally equipped to deal with environments in which direct decision-making is problematic, and (b) unable to "switch off" our socialized routines without considerable difficulty. However, it is not clear that human nature locks us into dispositions so unyielding that we cannot re-evaluate the moral status of our friendships periodically. Instead, it seems we can sometimes take a critical perspective toward our dispositions, potentially override them, and then choose either to continue to endorse them or else begin the process of ridding ourselves of their normative influence. A decisive argument on this point would require detailed empirical evidence about human psychology. However, in the absence of such evidence, many examples from literature and cinema are stacked against Mason, i.e. examinations of the internal conflicts that people experience when their deeply ingrained dispositions to honor their relationships are incompatible with broader ethical duties. ${ }^{19}$ It is be-

18 I focus on Mason because her contribution to the debate has been the most influential, but I do not mean to single her out as the only one to defend the view that consequentialists ought to apply the counterfactual condition to a broad and rigid friendship disposition. See Earl Conee, "Friendship and Consequentialism," Australasian Journal of Philosophy 79 (2001): 161-79, 177; Matthew Tedesco, "Indirect Consequentialism, Suboptimality, and Friendship," Pacific Philosophical Quarterly 87 (2006): 567-577, 572; and Edmund Henden, "Restrictive Consequentialism and Real Friendship," Ratio 20 (2007): 179-93, 184-87.

19 A comprehensive list of examples hardly seems necessary here. It is worth noting, though, that the type of situation at stake can be found in a range of cases so diverse as to stretch from ancient Greek mythology, e.g. Agamemnon's choice to sacrifice Iphigeneia, to modern instances of nihilist teenage melodrama, e.g. River's Edge (1986). Even the well-known quote from E.M. Forster ("If I had to choose between betraying my country and betraying my friend, I hope I should have the guts to betray my country") presumes that our dispositions are flexible enough to permit difficult choices between competing obligations. See E. M. Forster, "What I Believe," in Two Cheers for Democracy (London: Edward Arnold, 1972), 67-77. 
cause we agonize about these conflicts that this art has a profound impact upon us, and the tension we vicariously experience through it is indicative of the fact that we have the flexibility to choose against even deeply internalized dispositions. ${ }^{20}$

If we acknowledge that agents sometimes ought to dispense with the commitment to indirect decision procedures and instead evaluate, and potentially terminate, particular friendships in more direct consequentialist terms, our only remaining option is to accept the messy middle ground between Mason's proposal and the self-defeating application of a criterion of rightness to every instance of decision-making. ${ }^{21}$ Thus, the counterfactual condition of the sophisticated consequentialist must not be applied to individual acts, nor can it be applied to a comprehensive pro-friendship disposition; instead, the sophisticated consequentialist must "seek to lead a different sort of life" often enough to avoid morally indefensible acts of friendship, but not so often that she precludes herself from friendship by exhibiting a diminished capacity for the sense of personal commitment that makes it so specially valuable. This may sound so sensible as to be trite, but striking this balance is a nontrivial challenge. It involves complicated empirical estimates and the ability to routinely, but not permanently, suppress direct consequentialist evaluation.

It is a challenge, however, that is, in principle, mathematically tractable. It leaves agents with a complex epistemic challenge, but not a theoretical impasse. 22 This is an important distinction, because consequentialists ought to be accustomed to swallowing complex epistemic challenges as long as they are not insoluble. Whether it is foreseeing the long-term impact of actions

${ }^{20}$ Mason has also drawn criticism on this point from Candace Upton, who proposes a "contextual account of character traits" that is said to be both superior to the traditional account presupposed by Mason and still capable of granting the sophisticated consequentialist the capacity to be a genuine friend. See her "Context, Character and Consequentialist Friendships," Utilitas 20 (2008): 334-47.

${ }^{21}$ Strictly speaking, there is at least one other option: one can retain the Mason position that sophisticated consequentialists will not reject suboptimal friendships but claim that all counterintuitive examples are not genuine instances of friendship. This position is defended by Tedesco in "Indirect Consequentialism." He claims that Mason's pro-friendship disposition should be understood as endorsing only those relationships that are consistent with the commendable features of friendship, e.g. love, respect, etc. Thus, "Problematic friendships get rejected not because of any moral calculation or objective analysis, but rather because they simply don't fit with the way we understand friendship that makes us value it so deeply in the first place." (574) This is an economical way of salvaging Mason's position, but the empirical facts about our need for social relationships are not so neatly consistent with the limits of praiseworthy relationships. In other words, it is possible for the sort of friendship necessary to keep me emotionally intact to provide me with prima facie reasons to perform immoral actions. As Philip Pettit once reminded me, "A friend is someone who will help you move; a true friend is someone who will help you move a body." There is irony in this aphorism, but there is also considerable truth in its suggestion that friendship can lead to immoral behavior. On this particular point, I agree with Dean Cocking and Jeanette Kennett, "Friendship and Moral Danger," Journal of Philosophy 97 (2000): 278-296.

22 For a dissenting view, see James Griffin, "The Human Good and the Ambitions of Consequentialism," Social Philosophy \& Policy 9 (1992): 118-32, 128-9. 
over time or comparing the value of different kinds of goodness, it is a recurring strategy for consequentialists to embrace the mind-boggling complexity at stake and then set themselves the task of making the best approximations possible. This, I submit, is precisely what consequentialists ought to do when trying to estimate the point at which to apply the counterfactual condition and subsequently act in ways that may not be compatible with their commitments to their friends. The empirical factors in play may be exceedingly complex, but this should not deter consequentialists from endorsing flexible dispositions that track this complexity as best as can be expected for agents with our distinctly human faculties and limitations.

\section{III}

What follows is an initial attempt to survey the empirical factors that determine when a sophisticated consequentialist agent ought to stop suppressing her criterion of rightness and consider acting against the internalized dispositions that normally prevent her from ending friendships prematurely. I aim to explicate these empirical factors because they are often glossed over too quickly in a literature that is primarily focused on whether it is possible, in principle, for a consequentialist to have friends. However, I have a second aim in so far as I hope to illustrate just how complicated each of these empirical factors is when subjected to scrutiny. I seek to impress upon the consequentialist that she should embrace the fact that there is no easy way of employing indirect decision procedures to accommodate friendship. Instead, the sophisticated consequentialist should accept that she is destined to work continuously at finding the best balance possible between stable character dispositions and the judgment necessary to avoid grossly suboptimal acts.

\section{Friends, Lovers and Acquaintances}

The most obvious place to start is the fact that the "friendship" objection covers a broad range of cases, including everything from close family relations to friends with whom we share only a tenuous connection. Distinguishing between the various kinds of personal relationships is important: if we want to know how strong a disposition for loyalty ought to be, it matters greatly if we have in mind a disposition to act for the sake of close family members or a disposition to act for the sake of less significant friends. It is a fairly safe empirical estimate to claim that overall goodness is promoted if humans are disposed to care so deeply for family that they are averse to sacrificing these relationships. At the other end of the spectrum, spending considerable time and money on distant friends is not likely to be justified by even the most subtle, long-term estimates when strangers remain in dire need of aid. The middle ground between these two options is vast. How much of one's life must be protected from the demands of maximization to feel secure, energized and thus capable of promoting increased long-term good- 
ness? It is reasonable to believe that humans are more productive moral agents if they feel emotionally validated through personal relationships. ${ }^{23}$ Yet a law of diminishing returns surely applies at some point, and appealing to long-term calculations to justify resources spent on an extensive social circle seems a self-absorbed rationalization to avoid consequentialist obligations.

Consider the case of Ralph Nader. According to reports from coworkers, Nader is uniquely driven and has very few close personal relationships. He is apparently quite charismatic, humorous and capable of drawing strong feelings of allegiance from those with whom he interacts. Nevertheless, he is said to live an isolated personal life like that of a "priest or a monk" with no romantic relationships, and he consciously refrains from honoring any bonds of loyalty that detract from the most efficient pursuit of his social aims. ${ }^{24}$ It is, of course, a matter of heated controversy whether all of Nader's aims are justifiable given his alleged spoiler role in the 2000 and 2004 U.S. elections, but that is a separate issue. What is important for the consequentialist is the fact that he provides an example of what is psychologically possible, i.e. choosing to forsake friendship to work for the common good and not experiencing the emotional burnout that allegedly leads to self-defeating

23 Something like this hypothesis would seem to be grounding Aristotle's claim that, "for an isolated person life is difficult, for being continuously active is not easy by oneself, but is easier in the company of people different from oneself, and in relation to others." See Nichomachean Ethics, C. J. Rowe trans., Sarah Broadie ed. (Oxford: Oxford University Press, 2002) 1170a4-7. The fine details of how Aristotle justifies this claim, given his commitment to the self-sufficiency of human flourishing, are a matter of ongoing debate. See Elijah Milgram, "Aristotle on Making Other Selves," Canadian Journal of Philosophy 17 (1987): 361-76; and Nancy Sherman, "Aristotle on Friendship and the Shared Life," Philosophy and Phenomenological Research 47 (1987): 589-613. In terms of differentiating the degrees of commitment owed to family and friends, Aristotle offers observations that are, depending on one's fondness for his ethics, either vacuous or inspired: "So that one should not assign the same priority to everyone, nor everything to one's father, just as Zeus does not get all the sacrifices, is clear enough; and since different things are owed to parents, brothers, comrades, and benefactors, one should assign to each what belongs to them and what is fitting in their case." (1165a1418)

${ }^{24}$ Note, for example, Nader's bitter public attack of Joan Claybrook, a former member of his consumer advocacy group who then moved on to work for the Carter administration in the National Highway Traffic Safety Administration. When Claybrook supported giving longer lead times for automakers to include air bags in their vehicles (her reasoning being that doing so was necessary to avoid a veto of the proposed bill), Nader issued a vicious condemnation of her that was publicized in The Washington Post (Dec. 1, 1977). In response to whether this attack was excessive given their relationship, Nader's view is strikingly similar to that of a straightforward consequentialist: "My compass was the people on the highway. I was working, in effect, as a trustee for people on the highway, so things like associates, friendships, sentiment are secondary to pushing life-saving standards into law. [...] Personal loyalty cannot come at any price. It becomes an indulgence. You ask yourself, 'Personal loyalty for what?' Well, for marching shoulder to shoulder to an accomplished objective. But if that no longer is the case, then what's the function of personal loyalty? It's unadulterated, mawkish sentiment while people are dying needlessly on the highway." Quoted from the documentary An Unreasonable Man (2006). 
results over time. Nader has been working for the common good for more than 50 years and shows no signs of burning out.

Thus, Ralph Nader ought to serve as a cautionary tale for consequentialists who want to avoid indulgent rationalizations, yet it is not obvious that all of us are similarly equipped to forsake emotional attachments and ceaselessly promote the good without becoming demoralized. It might be the case that he is an anomaly who is not indicative of what the average human agent requires in terms of emotional security. Most of us feel that it would be unbearable, not just unpleasant, to work tirelessly without the emotional refuge that our personal relationships provide. More importantly, Nader's sense of social justice originated from being raised in a stable, caring family environment. Even if adult human agents can renounce all personal relationships to promote the good, Nader's life as a whole suggests that such agents are only possible after we assume the prior existence of such relationships in the form of emotionally secure family bonds.

\section{Human Socialization}

The strongest argument for the non-maximizing partiality allowed within sophisticated consequentialism is the empirical claim that certain basic family relations are necessary for humans to develop into the kind of appropriately socialized agents who recognize the normative authority of moral obligations. Moral education for humans is not a matter of learning rules of conduct via some straightforward intellectual exercise. The process by which we acquire moral judgment (so insightfully observed by Aristotle) requires close relationships between children and their overseers. Without a relationship of trust and commitment to a child's well-being, it would not be possible for each of us to learn what we all take for granted as adults: an ability to perceive the needs of others and recognize their moral significance. Elizabeth Ashford summarizes the point nicely: "It is only in the context of a loving personal relationship that our concern for a person is sufficiently intense to mirror the moral importance of how another person's life goes.” ${ }_{25}$ Thus, sophisticated consequentialism has a formidable argument for shielding at least some relationships characterized by partiality from the otherwise ubiquitous obligation to promote the most impartial goodness possible.

Yet, despite the formidable nature of this argument, its scope is unclear. For how long must caregivers remain unhesitatingly committed to their own children when others are in need? How soon after that, if at all, can we expect these caregivers to temper their feelings of love and concern for their own children so they can devote more resources to others? The intense dedication exhibited by parents for their children suggests that this is an area where questions about the flexibility of human nature have special signific-

25 See Elizabeth Ashford, "Utilitarianism, Integrity, and Partiality," The Journal of Philosophy 97 (2000): 421-39, 436-37. 
ance and a complexity all their own. It also remains to be seen what kinds of environment are compatible with children receiving an adequate moral education. Recent hysteria about children being raised by same-sex couples aside, we do not yet know the range of family units that are compatible with the emotional security required for children to flourish. Even in the case of alleged harms associated with raising children in a Kibbutz environment, they are not prevented from developing into emotionally stable moral agents. ${ }^{26}$ Stability and "family values" of some kind are necessary for the socialization of children, but it is precisely because we do not know the range of successful options that this term has acquired such ugly political baggage.

These complications, and surely others, reveal that even the strongest argument in the sophisticated consequentialist arsenal for allowing agents to give priority to their own personal relationships is more complex than it initially appears. The consequentialist can plausibly maintain that the dedication required for successful moral education of children is a more effective strategy than purely impartial maximization, but she ought to concede that when it comes to specifying the shape and the extent of the partiality granted to those responsible for nurturing children, it is unclear what forms of partiality can be protected and when the threshold is reached for consequentialist parents to set aside their intense dedication to their children and act for the general good.

\section{Recognizing the Limits of Friendship}

Let us provisionally assume that the prior two issues are resolved so that a certain range of relationships can be considered justified forms of partiality and that we can establish the necessary strength of the dispositions for these relationships if we are to prevent self-defeating forms of emotional burnout. A further difficulty still exists in the form of an epistemic dilemma facing agents trying to decide if they are in circumstances unusual enough to justify disregarding the influence of their normally reliable dispositions for remaining loyal to their friends, i.e. circumstances in which one ought to revert back to the direct influence of a consequentialist criterion of rightness. Unless one is willing to opt for the Mason proposal and claim that a general friendship disposition should not be distrusted under any circumstances (short of those that trigger the entire disposition to be disavowed), the sophisticated consequentialist must accept that an odd challenge exists in terms of being able to recognize when she should "pull the ripcord," so to speak, and stop operating on dispositions that have been internalized for the purpose of preempting direct consequentialist decision-making.

26 The diminished capacities for personal attachment allegedly exhibited by Kibbutz children are not only moderate from a consequentialist perspective when extreme poverty exists, but they also are potentially offset by increased capacities for expansive social awareness. See Melford Spiro, Children of the Kibbutz: A Study of Child Training and Personality (Lincoln, NE: iUniverse.com Inc., 1999). 
This challenge invites the psychological objection to two-level consequentialism so prominently articulated by Michael Stocker. ${ }^{27}$ According to this objection, it is not feasible as a matter of human psychology for agents to regularly act on indirect decision procedures yet retain the ability to periodically revert back to direct decision-making in special circumstances. The claim is that there is something profoundly unhealthy about the mind of an agent who is conditioned, as a matter of standard operating procedure, to avoid terminating friendships on grounds of suboptimality, yet who retains this ability for special situations that trigger her ordinarily suppressed criterion of rightness. The worry is illustrated by Railton's original example of Juan: an agent who routinely performs acts that are judged as "wrong" according to his criterion of rightness, e.g. buying a train ticket to visit his disheartened wife rather than donating the money to Oxfam. ${ }^{28}$ It seems as if something psychologically odd is occurring in the mind of an agent who is aware of his criterion of rightness but only sometimes gives it direct decisionmaking authority.

As noted earlier, critics like William Wilcox believe this psychological difficulty is serious enough to rule out sophisticated consequentialism. Railton, on the other hand, sees no problem within the mind of a sophisticated consequentialist agent. ${ }^{29}$ The truth is somewhere in between. Consequentialists like Railton are right to dismiss critics if they think the theory should be written off without presenting empirical evidence to back up the claim that the psychological problems they identify are insuperable. Yet one cannot be complacent about the practical challenge associated with sporadically acknowledging the decision-making authority of a criterion of rightness that is routinely inconsistent with one's ordinary, indirect decision-making procedures. Said another way, recognizing the point at which garden-variety suboptimality crosses over into gratuitous suboptimality is not psychologically straightforward. To succeed at this task, the consequentialist must internalize a disposition to disregard the practical influence of her criterion of rightness, yet she must remain capable of recognizing when a threshold has been

27 See "Values and Purposes: The Limits of Teleology and the Ends of Friendship," The Journal of Philosophy 78 (1981): 747-65; and "How Emotions Reveal Value and Help Cure the Schizophrenia of Modern Ethical Theories," in How Should One Live?, Roger Crisp ed. (Oxford: Oxford University Press, 1996), 173-90. For responses, see Barbara Herman, "On the Value of Acting from the Motive of Duty," The Philosophical Review 90 (1981), 359-82; Marcia Baron, "The Alleged Moral Repugnance of Acting from Duty," The Journal of Philosophy 81 (1984), 197-220; and Scott Woodcock, "Moral Schizophrenia and the Paradox of Friendship," Utilitas 22 (2010), 1-25.

28 See "Alienation," 157-60.

${ }^{29}$ Railton claims that, "The sophisticated consequentialist need not be deceiving himself or acting in bad faith when he avoids consequentialist reasoning." Ibid., 154. He is not alone when it comes to dismissing the psychological difficulties related to sophisticated consequentialism. See R. M. Hare, "Comments," in Hare and His Critics: Essays on Moral Thinking, Douglas Seanor and N. Fotion eds. (Oxford: Clarendon Press, 1988), 199-293, 289; and Norcross, "Consequentialism and Commitment," 398-401. 
reached and the decision-making authority of her criterion of rightness ought to be reinstated. ${ }^{30}$

The solution required here bears some similarity to Herbert Simon's well-known proposal for satisficing as a form of decision-making that economizes on the substantial information costs associated with directly evaluating one's available opportunities for maximizing profits. ${ }^{31}$ Satisficing has been extensively discussed in the consequentialist literature, but it is important to note that the challenge presented by friendship is not the same as the challenge for which satisficing provides a solution. ${ }^{32}$ The key difference is the fact that the dilemma generated by friendship is not a matter of information costs. It is instead a situation in which it is advantageous to act on a commitment to a long-term decision procedure and deliberately avoid moment-tomoment maximization even if one has access to full information. In an economic context, if costless information arises demonstrating that a better option is available, there is no reason to hesitate: one ought to immediately ab-

30 This way of describing the challenge at stake may give the impression that it is specific to the version of sophisticated consequentialism proposed by Railton, i.e. a version according to which agents are disposed to routinely act against their own criterion of rightness. This peculiarity, which is brought to the fore in the Juan example, does not sit well with all consequentialists. (See Hooker, Ideal Code, 75 and Elinor Mason, "Against Blameless Wrongdoing," Ethical Theory and Moral Practice 5 (2002): 287-303.) However, it is important to note that the challenge of knowing when to break from internalized dispositions is not specific to any one form of consequentialism. It is highlighted by blameless wrongdoing in Railton's sophisticated consequentialism, but the epistemic challenge arises in different forms in different theories. For example, in Brad Hooker's rule consequentialism there is no divergence between the criterion of rightness and what the theory recommends as dispositions for its agents, because a right action is one that is not "forbidden by the code of rules whose internalization by the overwhelming majority of everyone everywhere in each new generation has maximum expected value." (Ideal Code, 32) Nevertheless, Hooker claims that this code of rules will include a "disaster avoidance" rule. (ibid., 98-99) This rule is essential to avoid counterintuitive results in unusual circumstances, yet it creates an epistemic challenge for agents trying to recognize when they face a true "disaster." The existence of extreme poverty cannot be interpreted as a constant, ongoing disaster, or rule consequentialism collapses into extremely demanding act consequentialism. At the same time, one does not want rule consequentialists to be incapable of recognizing extraordinary circumstances where they are specially situated to help those in desperate need, e.g. the lone child drowning in a shallow pond. The balance point here will not be the same as it is for the sophisticated consequentialist, but similar epistemic issues will arise for agents caught between a continuous ability to alleviate suffering and the fact that the best long-term dispositions for agents to internalize involve routinely disregarding this ability.

31 See Herbert Simon, "Rational Decision Making in Business Organizations," The American Economic Review 69 (1979): 493-513.

32 Note that the form of satisficing relevant to the present discussion is not the widely cited form proposed by Slote. The satisficing proposed by Slote is not a decision-procedure interpretation of satisficing; hence, it is unlike what is envisioned by Simon, i.e. a purely practical strategy according to which agents accept suboptimal results only because the costs of continuing to search for more profitable options are expected to outweigh the benefits. On this point, see Philip Pettit, "Satisficing Consequentialism," Proceedings of the Aristotelian Society, Sup. 58 (1984): 165-76, 169-72. 
andon one's satisficing decision-procedure and seize the more profitable opportunity. In the context of friendship, one knows from the outset that, at any given moment, more efficient opportunities to promote goodness will be available compared to privileging one's friends - it is precisely the ability to avoid impartial maximization that the internalized disposition for loyalty to one's friends is meant to encourage.

In this respect, the challenge more closely resembles the situation facing Ulysses as he prepares to encounter the Sirens. The consequentialist must bind herself to a long-term decision procedure like Ulysses to the mast. Yet this comparison is also imperfect, for the consequentialist should not irrevocably bind herself to an internalized disposition for friendship. As we have seen, she should instead leave open the possibility of pulling the ripcord and reverting back to direct evaluations of her circumstances. The other key difference between the situation of Ulysses and that of the consequentialist is the fact that the "precommitment" on the part of the consequentialist is not meant to overcome future weakness of will. ${ }^{33}$ Rather than being a mechanism to prevent future irrationality, the precommitment on the part of the consequentialist is a mechanism used to prevent the proper execution of her criterion of rightness on a moment-to-moment basis. ${ }^{34}$

Ultimately, then, the core epistemic problem for a sophisticated consequentialist is a lack of explicit criteria for deciding when to stop suspending the authority of one's criterion of rightness. Her ethical theory cannot provide direct calculative guidance: from the perspective of the agent who invokes the theory's standards in a particular instance of decision-making, any deviation from her criterion of rightness will give her reason to pull the ripcord and ignore her disposition for friendship. Thus, it appears that sophisticated consequentialists will need some kind of intuitive ability to know when they ought to take up a reflective point of view and act on a direct criterion of rightness. ${ }^{35}$ As, we have seen above, this is what critics often object to

33 See Jon Elster, Ulysses and the Sirens: Studies in Rationality and Irrationality (Cambridge: Cambridge University Press, 1979). Elster proposes precommitment as an aid to reasoning that pre-emptively blocks future episodes of irrationality, e.g. the temptation to smoke, drink or eat unhealthy food.

${ }^{34}$ In this respect, the situation faced by the consequentialist is more akin to a Toxin Puzzle. See Gregory S. Kavka, “The Toxin Puzzle,” Analysis 43 (1983): 33-36.

${ }^{35}$ Philip Pettit suggests that consequentialists rely on what he calls moral "triggers" designed to snap agents out of ordinary moral thinking in exceptional circumstances. They are part of "virtual consequentialism" in which a commitment to consequentialist justification is only virtually present in routine decision-making in the sense that explicitly consequentialist reasoning lies dormant until thresholds are met that trigger critical reflection for our conscious deliberations. See "Consequentialism and Moral Psychology," International Journal of Philosophical Studies 2 (1994): 1-17, 14-16. This may seem like an esoteric proposal, but the impression that it is alien to human psychology is, I think, a product of just how unconsciously immersed we are in "virtual" reasoning in our daily life. A common example: I do not count the seconds waiting for a green light, nor do I even know how many seconds are supposed to elapse. Yet when the process takes too long, I am snapped back from my daydreams to focus on the problem. A more curious example: when I am running, I am somehow able to 
when it comes to the psychology of a revocable precommitment to honoring the loyalties of one's friendships, and they are correct that it is an odd challenge. However, the challenge is not as unusual as one might think. There are precedents for similar forms of decision-making in other contexts.

Consider, for example, the military convention that soldiers obey orders without questioning their justification. Teaching soldiers to follow this convention is not done by giving them a single, intellectual instruction. Rather, soldiers are habituated to accept the convention through an infamously rigorous process that leaves them with a deep aversion to taking up a reflective standpoint regarding the content of their orders. This amounts to an internalized disposition that must be resilient to be effective, yet we are all familiar by now with examples of how this disposition should not be irrevocably binding. How does the virtuous soldier know when she is in circumstances unusual enough that she ought to question the legitimacy of her orders? If she appeals to her guiding military standards to answer this question, she will be directed back to unhesitating obedience. The virtuous soldier must instead possess an intuitive ability to recognize when she ought to disregard her disposition for obedience and directly evaluate the merits of her orders.

Similar conventions exist for contexts in which it is impractical for physicians to justify their decisions to other health care professionals. A sizeable literature in nursing ethics exists on this topic, and a recurring theme is the need to strike a balance between the authority attributed to physicians, in light of their advanced formal training, and the fact that nurses acquire practical experience that gives them an intuitive sense of when it is appropriate to second-guess their instructions. ${ }^{36}$

A more familiar example for most of us is deciding when to change strategies in sports activities. For example, it is notoriously unwise to take up a reflective standpoint and start thinking about how to improve one's strategy while playing tennis. ${ }^{37}$ There may be considerable evidence that one's current strategy is not providing desirable results, yet the best response is often to defiantly avoid taking up a reflective standpoint and instead try to keep playing "in the moment" without hesitation. Thinking too much, in tennis

tell from twenty feet out which foot will land on an approaching curb and whether I need to adjust my stride. I cannot perform the relevant geometrical calculations to explain this curb detection system, and thinking about the curb is only triggered if adjustment is necessary. Yet I somehow manage to implement a form of "virtual stride adjustment" that brings reflective deliberation to the surface in unusual circumstances. These examples are anecdotal, but it is unlikely that I possess special abilities. It is more likely that these abilities go unnoticed because they are normally taken for granted.

36 See Helga Kuhse, Caring: Nurses, Women, and Ethics (Oxford: Blackwell Publishers, 1997), ch. 3 .

${ }^{37}$ Railton makes a similar point in "Alienation," 144. Another of Railton's examples is less familiar but more apt: the self-defeating nature of conscious deliberation while tightrope walking (154). 
and other sports, can be a curse. ${ }^{38}$ On the other hand, if one's efforts are consistently leading to poor results, at some point one ought to think about changing tactics.

A variety of other examples exist that range from knowing when to sell stocks to deciding each night whether or not to floss one's teeth. Not all are perfectly analogous to the epistemic problem facing the sophisticated consequentialist, but they illustrate that it is possible to operate on a standing disposition that postpones reflective evaluation on a moment-to-moment basis without precluding such evaluation if agents find themselves in circumstances abnormal enough to warrant critical reflection. It is no simple task, but it is more familiar than one might think.

\section{Friendship Conventions}

The last of the empirical factors I survey is perhaps the most obvious: the fact that agents rarely make clear-cut choices for or against their friendships. Instead, agents face a range of choices that preserve or subvert their friendships to various degrees. Furthermore, the kinds of acts that tend to strengthen friendships, or weaken them, are often demarcated in terms of conventions that sophisticated consequentialists ought to resist. The convention of buying friends gifts for birthdays and seasonal holidays is a case in point. It may well be necessary to demonstrate to friends that one assigns them preferential status, but most of us recognize that there is something perversely excessive about the resources, both in terms of money and time searching for gifts, that we devote to such occasions. This is a phenomenon keenly observed by those of us caught in the wake of Christmas spending norms, but the phenomenon is not restricted to any one holiday, religion or culture. ${ }^{39} \mathrm{It}$ manifests itself in various forms and degrees of magnitude, and in each case the question a sophisticated consequentialist must ask herself is, "Must I follow existing conventions and spend that much time and money to display my loyalty to my friends to fortify our mutual trust?" In at least some cases, the answer will be "no." 40

38 The common term for this in sports is "choking." Malcolm Gladwell effectively captures the paradoxical nature of this way of thinking too much, and contrasts it with "panicking," which involves perseverating on futile strategies and thus not thinking enough about other options in an emergency situation. See "The Art of Failure: Why Some People Choke and Others Panic," The New Yorker Aug 21 (2000): 84-92.

${ }^{39}$ Consider, for example, the controversy within the Jewish community over the excessive spending that is becoming more common at Bar and Bat Mitzvah celebrations, as well as the exaggerated costs so stoically endured by the parents responsible for financing many Indian and Chinese weddings.

40 In fact, a strict consequentialist will question whether favoratism is required of friendship at all. It may be that our integrity can be sustained by preferentially directed intimacy without favorable treatment. See Shelly Kagan, The Limits of Morality (Oxford: Oxford University Press, 1989), 367-69. 
What remains difficult to determine is the extent to which our current conventions artificially exaggerate the level of partiality required for friendship. It may seem as if the conventions requiring exchanges of resources between friends are no more than products of illicit marketing forces, but this risks underestimating how much human beings require credible displays of loyalty from their friends. Anyone can claim to be your friend. To provide a credible display of loyalty, a real friend may be required to give up resources no fair-weather "friend" would be willing to invest. As a display of loyalty, the sacrifice may be required of a friend in order to allay feelings of insecurity or mistrust. The size of the sacrifice need not be great; it need only be enough to deter imposters from presenting themselves as if they are committed to the fidelity of friendship.

Whether sacrifices of this kind are necessary for friendship depends on facts about human nature that are hard to estimate. The ubiquity of norms requiring such sacrifices need not reflect something unalterable about human nature: it might be a result of innate but revisable features of human nature, or it could a product of cultural transmission that is widespread but not indicative of any essential features of human association. ${ }^{41}$ These are notoriously difficult questions, and they ought to be addressed to determine the extent of what is necessary for us to secure the loyalty that gives friendship its special value.

What tends to prevent complications like this from being acknowledged is a tacit assumption that true friendship is an ethically pure relationship between rational agents who would not be mired with such inane insecurities and subsequent needs for displays of loyalty. Consider Aristotle's familiar distinctions between pleasure, utility and virtue friendships. ${ }^{22}$ It is tempting to think that what concerns us is agents who love and value each other exclusively because of the virtuous attributes they see in one another - agents whom one might think are immune from the insecurities that invite exaggerated displays of partiality. The thought is that only dubious forms of friendship, like those motivated by pleasure or utility, are vulnerable to exaggerated reassurance norms because they are grounded in the contingencies of mutual gain. An analysis of true friendship, one might think, can bypass these difficulties because they arise only in the face of uncertainty that a relationship will produce mutual benefit. True friends are secure in their camaraderie, for they each know that they necessarily aim at what is good.

${ }^{41}$ It could be the case, for example, that expectations of substantial sacrifices for the sake of friendship are the result of a cultural arms race that takes hold between competing loyalty norms, i.e. whenever a baseline level of sacrifice is established, the only way for Smith to demonstrate to Jones that she is truly loyal is to exceed this baseline and thereby contribute to a new, increased standard by which loyalty is judged. For an analysis of similar feedback loops, see Robert Boyd and Peter J. Richerson, Culture and the Evolutionary Process (Chicago: University of Chicago Press, 1985), 259-270.

42 Nicomachean Ethics, 1155b17ff. 
This line of thought should be resisted for at least two reasons. First, as we have seen with the Ralph Nader example above, it is not clear that this idealized understanding of friendship is feasible for most human beings, aspire as we might to someday become phronomoi.43 While on the path to full practical wisdom, friendship, as we commonly recognize it, is a mixture of all three Aristotelian archetypes, and even those aspects that faithfully track virtue friendship are complicated by the emotional trappings of agents who have not yet fully trained their characters to overcome base human insecurities and unequivocally find pleasure in the goodness of their friends. More importantly, what is feasible in terms of the perfection of each individual is not of primary significance for the consequentialist. If intimate but comparatively flawed relationships provide comfort for agents who will otherwise promote less good without these relationships, a sophisticated consequentialist must be willing to tolerate the emotional quirks of human nature in the service of maximization if these relationships are more efficient at generating collective benefits than the idealized forms of friendship that are possible for particular individuals striving toward their own flourishing. In other words, what we ought to value as ideal friendship is, for the consequentialist, an empirical question for which the sanitized ideal of Aristotelian virtue friendship is not necessarily the answer.

All of this complicates the more general problem of identifying acts that count as being consistent with friendship compared to those that violate its required partiality, and it is already a difficult contextual problem. Guidelines exist (e.g. give friends attention, care for them as extensions of yourself, etc.) and some limits are clear (e.g. throwing an unwilling friend in front of a speeding trolley seems a clear case of betrayal). But other cases are less ob-

${ }^{43}$ Moreover, even if this idealized conception of friendship is feasible, it might not be enviable for modern readers once the full implications of an Aristotelian perspective on friendship are acknowledged. In Books VII and IX of Nichomachean Ethics, one finds passages describing the need for friends to spend time with one another and enjoy each other's company - passages that are surely comforting and familiar for modern readers. Yet it is important to remember that, in ideal cases of virtue friendship, the close acquaintance that friends have with each other is crucially premised on the excellence of their characters. If we set aside all the vulnerabilities of human nature as byproducts of mere instrumental pleasure friendships, then the idealized form of friendship that remains is one in which agents care for each other in the strict sense of recognizing the enduring excellence of friends - an activity that is constitutive of flourishing, for one is appropriately directed toward what is fine and good. This is not relaxing at a bar or an unremarkable movie. This is an enhancement of the pursuit of excellence through interacting with a select group of "other selves" who are likeminded in their focus on acting rightly. This focus may not dominated by a duty to aid in the same way as it is for consequentialists (though one might wonder why not, given a fair interpretation of beneficence and the hard facts of global poverty), but it will entail comparably demanding expectations directed toward the intellectual virtues of contemplative inquiry. The highly idealized conception of Aristotelian friendship is thus in danger of bringing us back full circle to an alienating view of human agency, i.e. one in which agents are required to strictly pursue the good without any prerogatives to indulge in the idiosyncratically personal aims that make our individual lives meaningful. 
vious. If I break a promise to meet a friend for brunch because I watched a heart-wrenching documentary about child soldiers in Africa, stayed up all night writing letters to various governments and political organizations and then fell asleep, is this a minor act of betrayal or does it fall within the rightful terms of a friendship? How many of such instances can a friendship endure? As a single case, a friendship ought to be able to overcome an offence this trivial for the sake of a justifiable cause, but how many times can a friend stand you up before you suspect she is no friend at all? For a sophisticated consequentialist, the ideal dispositions for loyalty must strike a delicate balance between unraveling the stability of one's friendships and being able to recognize when trivial acts of betrayal can be safely accommodated by the rightful terms of these relationships.

\section{V}

By ending my survey here, I do not mean to suggest that these four empirical factors are exhaustive of the considerations at stake for a sophisticated consequentialist to determine the limits of her friendships. My point is instead that even the most prominent empirical factors at stake are more complicated than one might initially expect. The complexity of additional factors, of which there are surely many, will only reinforce my conclusion that the calculations required for a sophisticated consequentialist to recognize the limits of her friendships are more complicated than is normally acknowledged.

The fact that the preceding analysis exposes rarely disclosed levels of complexity facing sophisticated consequentialism may at some points give the impression that I aim to establish an argument against the theory. It would not be the first time that immense complexity has been cited as a reason to reject consequentialism, but I have the opposite aim. I believe that addressing the complexity present in sophisticated consequentialism is advantageous both because (a) given the problems with endorsing a rigid profriendship disposition like the one proposed by Mason, embracing this complexity helps to offer the strongest possible formulation of consequentialism in light of the friendship objection, and (b) it should be viewed as a virtue of consequentialism that it appropriately reflects the complicated ethical status of maintaining personal relationships in a world of intense need. An ethical theory ought to provide clear normative guidance, but this clarity must be balanced with a commitment to truthfully dealing with the messy details of how one ought to live in tragically non-ideal circumstances. Acknowledging the intricacy of the empirical considerations related to friendship helps to illustrate that consequentialism is well positioned to achieve this goal. Its simplicity at the level of a criterion of rightness provides an enduring source of guidance for moral inquiry, yet its empirical complexity keeps it attuned to the challenges facing human agents in realistic circumstances.

In this respect, sophisticated consequentialism ought to celebrate the fact that it provides no simple response to the friendship objection. Much as 
those of us living in affluent conditions may want a theory to give us an unlimited permission to protect our personal relationships from the scope of what can be sacrificed for the greater good, this would not be consistent with what careful reflection about our situation reveals. People die needlessly every minute of the day. One need not be a consequentialist to recognize that this generates serious moral obligations, ${ }^{44}$ and the consequentialist ought to embrace the fact that she confronts these obligations honestly. She ought to pride herself on the fact that the only respite her theory offers from these obligations is generated by intricate empirical calculations regarding the limits of human sociality and sacrifice. The respite should not be simple. It should not be obvious. If it exists at all, it should be based on the kinds of complicated empirical questions that the sophisticated consequentialist must address to determine when she ought to abandon her friends for the greater good.

Scott Woodcock

University of Victoria

Department of Philosophy

woodcock@uvic.ca

44 See, for example, Garrett Cullity, "International Aid and the Scope of Kindness," Ethics 105 (1994): 99-127; Ashford, "Utilitarianism, Integrity, and Partiality"; and Caspar Hare, "Rationality and the Distant Needy," Philosophy \& Public Affairs 35 (2007): 161-78. 